\title{
EDITORIAL
}

\section{MEMÓRIA E IDENTIDADE PROFSSIONAL: PRIMEIRO SIMPÓSIO IBERO-AMERICANO DE HISTÓRIA DA ENFERMAGEM (BRASIL, OUTUBRO 2007)}

Paulo Fernando de Souza Campos ${ }^{1}$, Taka 0 guisso², G enival Fernandes de Freitas ${ }^{3}$ ${ }^{1}$ D outor em H istória. Pós-doutorando da Escola de Enfermagem da U niversidade de São Paulo, Departamento de O rientação Profissional. Bolsista FAPESP. 2Professora Titular da Escola de Enfermagem da U niversidade de São Paulo, Departamento de O rientação Profissional. Líder do Grupo de Pesquisa História e Legislação da Enfermagem.

${ }^{3}$ Professor Doutor da Escola de Enfermagem da Universidade de São Paulo, Departamento de O rientação Profissional.

Durante muito tempo a História, como a história de todos os homens (essencialmente política, vista de cima e escrita por grupos hegemônicos secularmente instituídos, oriundos do velho mundo) caracterizava a única possibilidade de verificação do passado. Hermeticamente fechada, sua escrita identificava como histórico somente grandes feitos realizados por homens ilustres, autointitulados condutores da história. Os inominados (mulheres e homens comuns) eram considerados insignificantes. Sem merecer atenção eram relegados, excluídos, postos à margem da história por assumirem posições consideradas inferiores.

No Brasil, a escrita de uma história menos generalizante, valorizada muito mais pelo modelo teórico-filosófico em detrimento das experiências humanas, aconteceu sob o signo da interdisciplinaridade. Em consonância com outros países, a produção historiográfica nascida da recusa de uma história tradicional, preconizava que historiadores, ao escrever a história, não poderiam privilegiar o grande tempo dos acontecimentos, selecionar fatos considerados relevantes (fundados no econômico) e escrever uma história generalista, esquemática.

Para tanto, era preciso escrever uma história a contrapelo, que narrasse experiências vividas por homens e mulheres, seus feitos, sua cotidianeida- de, como propunham os historiadores ingleses ligados a new left ou os franceses da nouvelle histoire. Os movimentos de historiadores interessados na ampliação do universo de análise e de referência histórica contribuíram, nesse sentido, ao conquistar novos objetos, novas abordagens e novos problemas às investigações acerca das experiências humanas, ampliando, sobremaneira, o ofício do historiador.

Neste processo, as mulheres assumiram papel de destaque: no bojo das transformações, a história das mulheres destituiu limites que encerravam o passado e as pessoas que dele participaram na esteira das ações masculinas. Quase nunca mencionadas pela historiografia dominante, as mulheres eram consideradas subalternas, diminuídas em suas ocupações e fazeres. As explicações atingiam inclusive a anatomia de seus sexos, pensado desde os gregos como algo embotado, não desenvolvido, como explica Thomas Laqueur ao escrever o livro "Inventando o Sexo". A supremacia e dominação masculina, erigidos por dogmas e tabus que as eliminavam do processo histórico, parecia então encontrar seu fim.

A mulher assumiu lugares diversos, destacando-se no âmbito social. Contudo, sua participação no processo histórico sofreu (e ainda sofre) impo- 
sições da dominação masculina. Exemplar, nesse sentido, é a profissionalização da enfermagem. A história da enfermagem moderna revela forte influencia da dominação masculina na construção histórica da arte e ciência do cuidado: as enfermeiras eram simbolicamente identificadas como dóceis, frágeis, carinhosas e abnegadas (exaltando a fragilidade e vulnerabilidade da mulher, ao mesmo tempo que representava o hospital como extensão do lar), como "religiosas sem o hábito" (enaltecendo a idéia de submissão como inerente à condição feminina) ou ainda como grande mãe (representação erigida no seio dos grandes conflitos bélicos que assolaram o século XX). Mesmo reconhecidos, os lugares assumidos pelas mulheres reiteravam estereótipos que as sub-julgavam.

Ainda que perpassada por pré-conceitos, é possível afirmar que a profissionalização da enfermagem teve papel preponderante na emancipação feminina. Todavia, ao reiterar à ação do cuidado a partir das qualidades da feminilidade (nem sempre compatíveis e aceitáveis pelas mulheres, sobretudo as que negam a natureza) a profissionalização e o modelo nursing proposto originalmente por Florence Nigthingale (1820-1910) implicavam ser verdade construções discursivas que, em última instância, visavam controlar e esquadrinhar as mulheres; como nos relata Élizabeth Badinter em seu livro "O Mito do Amor Materno".

A história da enfermagem sugere muitos questionamentos, alguns ainda sem respostas. A feminilização do cuidado é um dos problemas que perpassam a historiografia sobre o tema, que raramente considera o período pré-nightingaleano. Quando reconhecido, enaltece a marginalização das cuidadoras (sempre vistas como prostitutas, delinqüentes, prisioneiras), não abarcam a presença negra e masculina (amas, babás, monges, pastores, soldados), tampouco manifestações culturais assentadas na prática da cura e do que hoje identificamos como assistência, como permite entrever as telas pintadas por Paul Gauguin em sua passagem pelas ilhas da Polinésia, nas quais o pintor exalta e alia o cuidado ao transcendental, místico-religioso.

Tais inquietações norteiam as ações do Grupo de Pesquisa História e Legislação da Enfermagem, do Departamento de Orientação Profissional, da Escola de Enfermagem da Universidade de São
Paulo. Como ratificar a importância da história (da enfermagem) para a formação e orientação profissional? De que maneira avançar o debate em torno da profissionalização da enfermagem não apenas no Brasil, mas no mundo ibero-americano que lhe deu origem histórica? Quais as relações de interdependência existentes nos processos que levaram à instalação de escolas de enfermagem no Brasil, (erigidas em modelos europeu e norte-americano) e cuja importância se estendeu para outros países da América Latina? Para responder essas premissas se fez necessário encampar o movimento em curso (ainda que localizado) em prol do recrudescimento da história da enfermagem como um campo legítimo da formação profissional.

Neste sentido, foi proposto a realização da primeira edição do Simpósio Ibero-Americano de História da Enfermagem e que este recuperasse o debate em torno da memória e da identidade profissional. O evento, organizado e executado pela Escola de Enfermagem da USP, identificou três grandes eixos para as exposições: História das Instituições de Ensino, Assistência e Agremiações de Enfermagem, História de Vida e Antropologia dos Cuidados; temática esta proposta após visita técnica realizada junto ao Departamento de Enfermeria E.U.E. Universidad de Alicante em outubro de 2006, na qual pudemos observar a extensão e o alcance das investigações em torno de problemáticas que perpassam a trajetória históricocultural da enfermagem.

$\mathrm{O}$ primeiro eixo recuperou os movimentos de instalação de escolas de enfermagem (abordagem que permitiu múltiplas constatações, dado o volume de trabalhos inscritos) institutos de assistência, hospitais e espaços de atendimento nos quais a enfermagem atua com primazia, tais como casas de parto ou de amparo maternal, assim como a organização sindical, legislação e associações de classe como, a fundação da Associação Brasileira de Enfermagem, a construção de espaços assistenciais e suas transformações. O segundo eixo propôs a recuperação de experiências individuais ou de grupo no âmbito da enfermagem. Os temas implicaram pensar a atuação de homens e mulheres no campo da enfermagem, institucional ou não, enfermeiros, médicos e pacientes. O terceiro eixo evidenciou a multiplicidade de ações no campo do 
cuidado, sobretudo as que ultrapassam os limites impostos pela oficialização do ensino, da institucionalização da prática, avançando para terrenos pouco explorados tais como, o cuidado exercido por negros, das representações simbólicas da enfermagem, o cuidado exercido por religiosos, entre outros.

Participaram do evento com apresentação de trabalhos enfermeiros, historiadores e antropólogos de países da América Latina (Chile, Peru, Colômbia), Europa (Portugal e Espanha), África (Angola, Cabo Verde) e Ásia (Japão), este representado pela Presidente do International Council of Nurses - ICN, Dra. Hiroko Minami. Todas as regiões do Brasil encaminharam seus representantes que apresentaram trabalhos em consonância com os eixos temáticos propostos, enriquecendo e ampliando o pensar e o fazer a história no âmbito da enfermagem. A repercussão nacional e internacional permitiu o encontro de pesquisadores que, sintomaticamente, se alinharam em uma única direção: batalhar pela validação da área como campo de investigação que, para além dos conteúdos da orientação profissional, legitima a identidade profissional da enfermagem no Brasil e no mundo.

Os resultados alcançados pelo evento permitem considerar que a história da enfermagem, redimensionada pela cultura dos cuidados, deve ser valorizada como fundamental para o desenvolvimento da assistência. O reconhecimento das expe- riências que construíram os alicerces da profissão no universo ibero-americano, revelado pela ampla participação de pesquisadores de diferentes partes do mundo, é indicativo seguro de que a análise crítica e dialética dos caminhos percorridos pela enfermagem é meio eficaz para o fortalecimento da profissão. Sem o resgate da memória não há como sustentar a identidade profissional, não há como projetar o futuro ou as ações que dele farão parte.

$\mathrm{O}$ intercâmbio dos saberes voltados para a história da enfermagem possibilitou a primeira edição do Simpósio Ibero-Americano de História da Enfermagem, assinalando o compromisso com uma escrita da história que recupere experiências de homens e mulheres, ilustres ou inominados para, assim, reescrever a história dos cuidados.

O presente editorial de "Cultura de los Cuidados. Revista de Enfermeria y Humanidades" e a divulgação pela Associação Portuguesa de Enfermagem - APE, que encampou a organização e execução da segunda edição do evento, são indicativos seguros de que a história da enfermagem não se diluirá diante dos grandes desafios teóricometodológicos que enfrenta. Ao contrário, a força vital da História da Enfermagem e sua importância na formação do enfermeiro permanece sustentada pela continuidade do debate, pela composição de parcerias e pelo diálogo cada vez mais freqüente entre grupos de pesquisadores dos países que compõe o mundo ibero-americano.

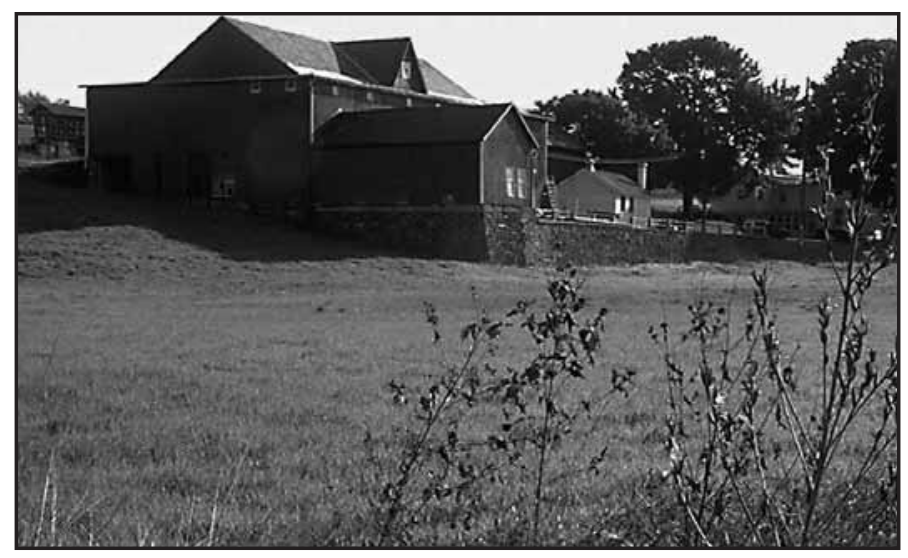

